\title{
О ПРОБЛЕМЕ ТРАКТОВКИ КАТЕГОРИИ «ОБЪЕКТ» В ПРАВОВЕДЕНИИ
}

\begin{abstract}
Аннотация: Теория права содержит много нерешённых проблем, которые, «пересекаясь» с проблемами правовой герменевтики, образуют терминологические коконы, опутывающие и скрывающие юридическую истину, препятствующие углубленному изучению правового материала, уточнению направлений научно-юридической рационализации, а также надолго лишающие нас понимания сущностных значений юридических терминов. Одна из дискутируемых проблем - объект в праве. Критически оценивая существующие трактовки, автор считает необходимым выработать единое понимание объекта в праве, которое может быть связано только с поведением субъекта права, образующим материально-правовое содержание правоотношения. Анализируя используемые термины «объект права», "объект воздействия объективного права», "объект нормы права», "объект воздействия правовой нормы», "объект регулирования правовой нормы», "объект субъективного права», "объект прав и обязанностей», "объект правового регулирования", "объект правоотношения», автор приходит к выводу о том, что единая позиция правоведов должна быть основана на признании только объекта правового регулирования (конституционно-правового, административноправового, гражданско-правового и т.д.) или объекта правоотношения. Связанность юридической формы и правового содержания правоотношения логически приводят к выводу об обоснованности концепта состава правоотношения, включающего юридическую форму, материально-правовое содержание, субъект права, объект и предмет правоотношения.

Ключевые слова: субъект права, объект правового регулирования, объект правоотношения, правовое регулирование, теория правоотношения, состав правоотношения, право, правоотношение, юридическая форма, фактическое содержание правоотношения
\end{abstract}

DOI: 10.7256/1994-1471.2014.3.9396

$\mathrm{H}$ аучная юридическая литература представляет различные взгляды на категорию «объект» в праве. Ассимиляция юридических смыслов привела к распространению алогичных соответствующих правовых терминов и неверному пониманию сущности правоотношения.

Давно выражен тезис о несостоятельности попыток «вымучивать» проблему объекта в отдельных отраслях права ${ }^{1}$. Однако до настоящего времени авторы терминологических конструкций «грешат» избыточным творчеством, представляя собственные трактовки объектов права. Например, А.А. Тедеев и В.А. Парыгина предлагают считать объектом налогового права «аналитическое исследование общественных отношений в сфере налогообложения» ${ }^{2}$, сходя с

См.: Халфина Р.О. Общее учение о правоотношении. М.: Юр. лит. - 1974. С. 215 (со ссылкой на позицию С.С. Алексеева; Алексеев С.С. Проблемы теории права, т. 1, Свердловск, 1972).

См.: Тедеев А.А., Парыгина В.А. Налоговое право: Учебник - М.: Изд-во Эксмо, 2004. С. 34. правовой плоскости обсуждения на уровень социологического осмысления проблемы.

Подобный опыт подпадает под смысл тезиca P.O. Халфиной, но в контексте нерешённой теоретико-правовой задачи актуализирует проблему объекта в праве и приводит к сомнениям относительно теоретико-познавательной диалектической ценности вышеприведенного тезиса.

Многолетняя неопределённость во взглядах, незавершённость диспутируемой проблемы объекта в праве позволяет продолжить её обсуждение.

Несколько десятилетий используются термины «объект права», «объект воздействия объективного права», «объект нормы права» («объект воздействия» или «объект регулирования правовой нормы»), «объект правового регулирования», «объект правоотношения», «объект субъективного права», «объект прав и обязанностей» ${ }^{3}$.

3 См.: Толстой Ю.К. К теории правоотношения. - Л.: Изд-во Ленинградского Ун-та. - 1959. - 88 с.

(C) Борисов Андрей Марксович

* Кандидат исторических наук, доцент кафедры конституционного и административного права, Курский государственный университет

[andrei_borisov@mail.ru]

305000, г. Курск, ул. Радищева, 33. 
Нам представляются некорректными термины «объект воздействия объективного права», «объект регулирования правовой нормы», «объект субъективного права», «объект прав и обязанностей».

Полагаем, что воздействие всегда оказывает субъект, а право (норма права), являющееся правовым средством, создаётся и используется или применяется им с определённой правовой целью. Норма права ничего не регулирует. Эта функция (регулирование) исполняется управомоченным субъектом на этапе нормативно регламентированного правотворчества при создании нового правила (установления новой нормы) для целей урегулирования общественных отношений. В этом случае норма права результат правотворчества, приобретающий социальное значение правового регулятора и имеющий специально-юридическое значение для своих адресатов.

Следующий этап реализации права связан с конкретным правоотношением, но тогда речь идёт не о регулировании, а об урегулировании конкретных общественных отношений с помощью ресурса права. Имеются в виду правоприменение (активное поведение), когда мы говорим о субъекте власти, и правоиспользование (активное поведение) - когда речь идёт о субъекте, не имеющим властных полномочий, но реализующим свои субъективные права и обязанности, например при заключении договора 4 . В случае правоприменения происходит урегулирование правовых ситуаций (отношений) посредством применения нормы (урегулирование на основе и в соответствии с нормой права) в рамках управленческой деятельности. Во втором случае урегулирование осуществляется на началах равностатутного положения участников правоотношения вне зависимости от характера общего (основного) правоотношения (управленческое или договорное). В случаях правоприменения и правоиспользования норма права - правовой инструмент для достижения определённого юридического результата, а результатом урегулирования окажется, в самом общем виде, новый статус участников правоотношения (удовлетворённые интерес, запрос, притязание или претензия).

4 Исполнение и соблюдение предполагают пассивное поведение субъекта. Однако связь с активным волепроявлением обнаруживается, например, в случае исполнения, если речь идёт о правоприменительной форме исполнения, имманентной управомоченному лицу (другая форма - непосредственная). В самом общем смысле исполнение (предписаний) и соблюдение (запретов) могут восприниматься как использование права с определёнными целями (выполнения определённой социальной функции - исполнение, защиты здоровья - соблюдение).
Повторимся, мы рассматриваем норму как средство правового регулирования.

Субъективное право, представляя собой идеальную абстракцию, нереализованную возможность, вероятностную правовую категорию не может иметь объект, который может быть установлен лишь при реализации участником правоотношения личного субъективного права посредством совершения определённых действий, связанных с исполнением, соблюдением, использованием или применением правовых норм, посредством которых лицо наделяется субъективным правом (например, правом притязать на что-либо) как материально-правовой возможностью иметь желаемое и как процессуально-правовой возможностью достичь своей цели. То же самое можно сказать об объекте прав и обязанностей.

Иными словами, объект обнаруживается лишь в деятельности субъектов права, состоящей из определённого ряда актов волевого поведения участников правоотношений (в данной статье мы не обращаемся к вопросу о сущностном содержании объекта).

В этом аспекте можно говорить только об объекте правового регулирования (конституционно-правового, административно-правового, гражданско-правового и т.д.) или объекте правоотношения, на что обращала внимание Р.О. Халфина ${ }^{5}$.

Констатируя наличие проблемы по вопросу об объекте правового регулирования, который, зачастую представляется одновременно и как объект права, и как предмет правового регулирования, отметим сохраняющуюся теоретическую неопределённость его известного содержания.

Под объектом правового регулирования понимаются общественные отношения или акты волевого поведения людей ${ }^{6}$ как условно материальная основа надстроечного правового отношения.

Смысловая идентичность, которая придана C.C. Алексеевым общественным отношениям и актам волевого поведения (союз «или) проявляет убеждение автора в том, что именно фактическое поведение лица можно рассматривать в качестве содержания общественного отношения. Это обстоятельство представляется важным для последующего рассмотрения вопроса о содержании правоотношения, при котором, как мы полагаем, следует логически спроецировать на правоотношение исходную

См.: Халфина Р.О. Указ. соч. С. 211.

6 См.: Алексеев С.С. Общая теория права: учеб. - 2-е изд., перераб. и доп. - М.: ТК Велби, Изд-во Проспект, 2008. С. 394. 
материалистическую установку на признание волевого поведения содержательным элементом общественного отношения и прийти к заключению о соответствующем значении правового акта поведения (волевой акт поведения, предусмотренный правом).

Однако мы не видим тождества между общественными отношениями и актами волевого поведения для того, чтобы рассматривать эти категории в качестве равнозначимых для целей их отнесения к объектам правового регулирования. Свойства объекта скорее обнаруживаются у категории, обусловливающей поведенческий акт (сознание), ибо правовое регулирование направлено на обеспечение сознательно-правомерного поведения лиц по поводу чего-либо как ожидаемый результат и цель публичного значения, заданное практическое проявление правосознания.

Конкретные общественные отношения, материальным содержанием которых являются акты волевого поведения, связанные с чем-либо, приобретают свойства предмета правового регулирования.

Если выделять общий и непосредственный объект правового регулирования в виде, соответственно, общественных отношений и действий (деятельности) их участников, то, во-первых, очевидна их несоотносимость в качестве однопорядковых категорий (общий и непосредственный объекты), какими они представлены в некоторых изданиях ${ }^{7}$, поскольку общественное отношение и его материальное содержание ${ }^{8}$ соотносятся как целое и содержательная часть этого целого. В связи с этим, полагаем, что непосредственный объект может отождествляться лишь с фрагментом общего объекта, а потому ему следовало бы, следуя рассматриваемому подходу, придать исключительно значение правоотношения, но не деяния (общее правоотношение военной службы включает в себя ряд правоотношений (части целого), составляющих первое (например, отношения по поводу военной тайны, субординационные отношения, дисциплинарные отношения и др.).

Во-вторых, с позиций предлагаемого концепта объекта и предмета правового регулирования в данном решении состоялось «замещение» объекта предметом.

Сложны и интересны вопросы о структуре и составе правоотношения, о выделении объек-

См.: Гойман-Калинский И.В., Иванец Г.И., Червонюк В.И. Элементарные начала общей теории права: Учебное пособие для вузов / Под общ. ред. д-ра юрид. наук, проф. В.И. Червонюка. - Право и закон, М.: КолосС, 2003. C. 102.

8 См.: Алексеев С.С. Указ. соч. С. 343, 355. та в правоотношении. Сложность обусловлена методологическими подходами к определению правоотношения, оценке его структуры и состава, а также каждого из его элементов.

Как юридическая связь участников общественного отношения ${ }^{9}$ правоотношение представляется «застывшей» правовой ситуацией.

Проблемность такого восприятия несколько снижает разъяснение о составе правоотношения (содержание, субъекты права, объект), в том числе о его материальном и юридическом содержании ${ }^{10}$. Отметим, что С.С. Алексеев рассматривает материальное и юридическое содержание правоотношения как стороны или стадии (состояния) единого содержания правоотношения, обращая внимание на его динамичность, и считает наиболее значимым решение проблем правоотношений, в том числе «на базе и в связи с общетеоретическими выводами и положениями философского уровня», с учётом материализации субъективных юридических прав и обязанностей в поведении людей, а также размышляет о перспективности материальной модели правоотношения ${ }^{11}$, с чем нельзя не согласиться. Однако автор не считает возможным рассматривать, например, материальное и юридическое содержание правоотношения «в качестве элементов и, следовательно, таких явлений, из которых складывается структура правоотношения», в отличие от Р.О. Халфиной, Б.Л. Назарова, Ю.Г. Ткаченко ${ }^{12}$, позиции которых подвергаются его критике.

Полагаем, что такая трактовка противоречива, поскольку являясь составляющими (сегментами) содержания как структурного элемента правоотношения, юридическая и материальная его формы приобретают свойства субэлементов правоотношения (в рамках концепта о трёхэлементном составе правоотношения).

9 «...правоотношения - это индивидуализированная связь, которая возникает на основе правовых норм между гражданами и иными лицами в форме субъективных прав и юридических обязанностей и поддерживается принудительной силой государства». См.: Сырых B.M. Теория государства и права: Учебник для вузов. - 4-е изд., стер. - М.: ЗАО Юстицинформ, 2005. - 704 с. С. 312; «Правоотношение - обусловленная интересами субъекта и возникающая непосредственно из закона либо фактических правомерных действий юридическая связь, стороны которой обладают субъективными правами и юридическими обязанностями». См.: Гойман-Калинский И.В., Иванец Г.И., Червонюк В.И. Элементарные начала общей теории права: Учебное пособие для вузов / Под общей ред. д-ра юрид. наук, проф. В.И. Червонюка. Право и закон, М.: КолосС, 2003. С. 359-370.

10 См.: Алексеев С.С. Общая теория права: учеб. - 2-е изд., перераб. и доп. - М.: ТК Велби, Изд-во Проспект, 2008. С. 343-345, 355-356, 376-377.

11 См. Алексеев С.С. Указ. соч. С. 344-345.

12 Там же. С. 376. 
Противоречивость позиции обнаруживается и в том, что автор говорит о «едином содержании правоотношения», но правоотношение, при акцентировании внимания в его определении лишь на юридическом содержании, как это делает С.С. Алексеев ${ }^{13}$ и другие авторы, «теряет» признак единого содержания и предстаёт лишь нематериально-правовой (идеальноправовой или должной, установленной законом) моделью правоотношения, а не собственно реальным правоотношением.

Подчеркнём, что сложившиеся трактовки правоотношения фактически «разрывают» его на две составляющие, признавая правовые возможности, но игнорируя фактические деяния. Следуя традиционному пониманию правоотношения, которому свойственно «чисто юридическое содержание» ${ }^{14}$, мы, учитывая вышесказанное, должны признать наличие объекта у «застывшей» правовой материи, обозначающей нечто не существующее в реальности (правовые возможности). Такая позиция получила справедливую критику Р.О. Халфиной более тридцати лет назад ${ }^{15}$.

С другой стороны, С.С. Алексеевым подмечены динамические характеристики правоотношения (стадии или состояния), которые, однако, у автора равнозначны по смысловому содержанию.

Считаем необходимым обратить внимание на следующее: стадия характеризует изменение правоотношения во времени в связи с совершаемыми субъектами права актами поведения, а состояние - есть качественное изменение правоотношения, происходящее вследствие совершения волевых актов поведения одной из сторон правоотношения. Первое обстоятельство обращает нас к динамике правоотношения, процедурной его стороне, в результате чего мы имеем «живую» картину правовой действительности в цепи реализованных прав и обязанностей, а не «застывший» фрагмент правовых возможностей. Второе требует особого внимания к промежуточным и конечным (на определённых стадиях) результатам развития правоотношения, в качестве которых нам видятся определённые характеристики структурных элементов правоотношения (например, изменение правового статуса участвующего лица).

13 «Это возникающая на основе норм права индивидуализированная общественная связь между лицами, характеризуемая наличием субъективных юридических прав и обязанностей и поддерживаемая (гарантируемая) принудительной силой государства». См.: Алексеев С.С. Указ. соч. С. 328.

14 Там же. С. 343.

15 См.:Халфина Р.О.Общееучениеоправоотношении.М.: Юр. лит. - 1974. С. 209-210.
«Замалчивание» в определениях правоотношения процедурно-поведенческой стороны и результата развития правоотношения формирует у заинтересованного читателя неполное представление о рассматриваемом предмете и его содержании. Распространённые в юридической литературе трактовки правоотношения свидетельствуют об отходе сообщества правоведов от материалистического восприятия правовой действительности, в основе которой лежат правовые (правомерные или противоправные) деяния участников общественных отношений.

Таким образом, предполагая, что в рамках правоотношения через совершаемые волевые акты поведения реализуются субъективные права и обязанности сторон, мы должны расширить определение правоотношения указанием на эволюцию данной юридической индивидуализированной связи, обусловленную совершением сторонами правоотношения определённых деяний, и итоговый правовой результат в виде реализованного или нереализованного интереса.

Рассматривая правоотношение как сложное образование, С.С. Алексеев отмечает, что оно «имеет определённое внутреннее строение» ${ }^{16}$.

Обратившись к Малому энциклопедическому словарю Брокгауза-Ефрона ${ }^{17}$ и Толковому словарю русского языка С.И. Ожегова и Н.Ю. Шведовой ${ }^{18}$, мы увидим, что речь идёт о структуре правоотношения. Аналогичный по своему содержанию термин - состав, который использует автор, называя основные элементы правоотношения, на первый взгляд вполне применим. Однако далее С.С. Алексеев утверждает, что понятие «структура» «при характеристике правоотношения применимо, по сути дела, только к юридическому содержанию», «структура правоотношения - это строение взаимосвязанных прав и обязанностей, подразделение их на группы, соотношение между ними» ${ }^{19}$. Поэтому, говоря о составе правоотношения, более обоснованной может выглядеть точка зрения, согласно которой правоотношения следует разделять на простые и сложные, но понимать

16 См.: Алексеев С.С. Указ. соч. С. 328.
17 «Структура, лат., внутреннее строение...». См.: Малый энциклопедический словарь: в 4 т. Т. 4 / Репринтное воспроизведение издания Брокгауза-Ефрона. - М.: TEPPA, 1994.

18 «Структура, -ы, ж. Строение (во 2 знач.), внутреннее устройство...». См.: Ожегов С.И. и Шведова Н.Ю. Толковый словарь русского языка: 80000 слов и фразеологических выражений / Российская академия наук. Институт русского языка им. В.В. Виноградова. - 4-е изд., дополненное. - М.: Азбуковник, 1999. С. 775.

19 См. Алексеев С.С. Указ. соч. С. 377. 
их не как «правоотношения с простой и сложной структурами» ${ }^{20}$, а как правоотношения с простым (отношения купли-продажи) и сложным составом (отношения государственной службы).

Словесно-терминологические тернии на пути к пониманию сущности правоотношения обусловили логическое заключение, с которым трудно согласиться.

Анализируя правоотношение, С.С. Алексеев характеризует его «как единство фактического материального содержания и юридической формы» ${ }^{21}$, тем самым выделяя два исходных и равнозначимых элемента правоотношения. Обосновывая стремление «выйти за пределы юридической формы», автор поясняет, что оно продиктовано «прежде всего, последовательнонаучной концепцией правоотношения, неразрывной связью юридической формы в правоотношении с его фактическим содержанием» ${ }^{22}$. В результате, проявляя широкий подход, автор определяет состав правоотношения, в который, наряду с содержанием, включает субъектов и объект правоотношения.

Мы же полагаем, что в этом случае следует говорить о структуре правоотношения.

Логический сбой обнаруживается в развитии концепта единства формы и содержания: обозначив два существенных элемента правоотношения, автор, выстраивая состав (структуру) правоотношения, «потерял», а точнее, умышленно вывел за рамки предмета рассмотрения его фактическое содержание. Игнорирование «неразрывной связи» юридической формы и материального содержания, на наш взгляд, не отвечает принципам последовательно-научной концепции правоотношения ${ }^{23}$.

Полагаем, что первая методологическая ошибка правоведов состоит в следующем: признавая неразрывность юридической формы и фактического содержания правоотношения в рамках такого структурного элемента правоотношения, как содержание, авторы такого концепта придали юридической форме значение содержания, допустив «ускользание» из поля зрения материальной стороны; вторая связана с определением правоотношения через элементы юридической формы (субъективные права и обязанности). Третья заключается в

\footnotetext{
20 Там же.

21 Там же. С. 343.

22 Там же.
}

23 Любая правовая концепция основывается на философии права, несущей в себе, в том числе, философские дуалистические представления о равнозначимости иде ального и материального. См.: Краткий философский словарь / Кириленко Г.Г., Шевцов Е.В. - М.: Филол. о-во СЛОВО: Изд-во Эксмо, 2003. С. 111-112. недооценке сферы распространения правовой материи, в результате чего фактическое содержание в виде актов поведения, направленных на реализацию юридического содержания правоотношения, не раскрыто как совокупность собственно правовых актов поведения.

Рассматривая правовой акт поведения как правовое деяние (действие или бездействие) согласно или вопреки установленным правилам, правомерные или неправомерные поступки, мы не можем не замечать главной характеристики актов поведения, связанной с юридизированностью значительного спектра общественных отношений и созданием юридически идеальных моделей поведения членов общества в государстве - они являются правовыми или неправовыми в рамках определённого правоотношения.

Подчеркнём ещё раз, что фактические акты поведения, в случае нормативного установления прав и обязанностей участников правоотношений, приобретают характеристику правовых актов поведения - правомерных (при соблюдении установленных правил), если говорить о конкретном правоотношении, или неправомерных (при нарушении правил) поступков, при которых возникает новое правоотношение, но оно не всегда сопровождается прекращением основного правоотношения (например, отсутствие государственного служащего на рабочем месте в течение определённого времени по неуважительной причине не прекращает отношений государственной службы).

Полагаем, что в этом случае мы вправе говорить не просто о материальном содержании, а о материально-правовом содержании правоотношения.

В этом аспекте материально-правового содержания общественного отношения возможно развитие взглядов на предмет правоотношения, с которым связан объект (будет рассмотрен в следующем материале) и на который может распространяться определённый правовой режим (например, правовые режимы собственности, авторства - гражданско-правовая сфера отношений, а правовой режим государственной тайны - административноправовая сфера; режим охраны труда - сфера трудовых правоотношений).

Анализируя юридическую и материальную составляющие правоотношения, мы должны заметить, что первая - есть модель правомерного или противоправного поведения участников правоотношения (Особенная часть КоАП РФ), юридическая форма правоотношения (уточним, что юридическая форма правоотношения описывает правовой статус сторон правоотношения, складывающийся из материальной и процессуальной частей). 
Вторая - собственно фактическое правовое поведение, правомерное или противоправное, на что обращает внимание и С.С. Алексеев, но не усматривает в этом повода к углубленному рассмотрению материально-правового содержания правоотношения и отражению его материальной стороны в определении правоотношения.

Небезупречно представляется данная тема и в иных изданиях юридического профиля.

Принимая во внимание вышеизложенное, мы приходим к новому концепту структуры правоотношения, включающего следующие элементы: юридическую форму; материальноправовой акт поведения; субъект правоотно- шения; объект правоотношения, предмет правоотношения ${ }^{24}$.

В этом случае, при соответствующей доработке термина правоотношения, устраняется первая проблема, происходит «оживление» правовой картины правоотношения, она дополняется материально-правовым содержанием и мы получаем возможность признать обоснованным выделение объекта правоотношения, который получает «право» на признание в «перекрестье» векторов актов поведения субъектов правоотношения и под воздействием правового поля какого-либо правового режима как результат развития правоотношения, предусмотренный нормой права.

\section{Библиография}

1. Алексеев С.С. Общая теория права: учеб. - 2-е изд., перераб. и доп. - М.: ТК Велби, Изд-во Проспект, 2008. - 576 с.

2. Гойман-Калинский И.В., Иванец Г.И., Червонюк В.И. Элементарные начала общей теории права: Учебное пособие для вузов / Под общей ред. д-ра юрид. наук, проф. В.И. Червонюка. - Право и закон, М.: КолосС, 2003. - 544 c.

3. Гуляихин В.Н. Структурно-функциональные особенности различных состояний правосознания человека // Вопросы права и политики. - 2012. - №2. - С. 90-116. DOI: 10.7256/23059699.2012.2.153.

4. Краткий философский словарь / Кириленко Г.Г., Шевцов Е.В. - М.: Филол. о-во СЛОВО: Изд-во Эксмо, 2003. - 480 с.

5. Малый энциклопедический словарь: в 4 т. Т. 4 / Репринтное воспроизведение издания Брокгауза-Ефрона. - М.: ТЕРРА, 1994. - 592 с.

6. Ожегов С.И. и Шведова Н.Ю. Толковый словарь русского языка: 80000 слов и фразеологических выражений / Российская академия наук. Институт русского языка им. В.В. Виноградова. - 4-е изд., дополненное. - М.: Азбуковник, 1999. - 944 с.

7. Сырых В.М. Теория государства и права: Учебник для вузов. - 4-е изд., стер. - М.: ЗАО Юстицинформ, 2005. - 704 с.

8. Тедеев А.А., Парыгина В.А. Налоговое право: Учебник / А.А. Тедеев, В.А. Парыгина. - М.: Издво Эксмо, 2004. - 864 с. .

9. Толстой Ю.К. К теории правоотношения. - Ленинград: Изд-во Ленинградского Ун-та. - 1959. $-88 \mathrm{c.}$

10. Халфина Р.О. Общее учение о правоотношении. - М.: Юр. лит. - 1974. - 340 с.

\section{References}

1. Alekseev S.S. Obshchaya teoriya prava: ucheb. - 2-e izd., pererab. i dop. - M.: TK Velbi, Izd-vo Prospekt, 2008. - 576 s.

2. Goiman-Kalinskii I.V., Ivanets G.I., Chervonyuk V.I. Elementarnye nachala obshchei teorii prava: Uchebnoe posobie dlya vuzov / Pod obshchei red. d-ra yurid. nauk, prof. V.I. Chervonyuka. - Pravo i zakon, M.: KolosS, 2003. - 544 s.

3. Gulyaikhin V.N. Strukturno-funktsional'nye osobennosti razlichnykh sostoyanii pravosoznaniya cheloveka // Voprosy prava i politiki. - 2012. - №2. - C. 90-116. DOI: 10.7256/23059699.2012.2.153.

4. Kratkii filosofskii slovar' / Kirilenko G.G., Shevtsov E.V. - M.: Filol. o-vo SLOVO: Izd-vo Eksmo, 2003. $480 \mathrm{~s}$.

5. Malyi entsiklopedicheskii slovar': v 4 t. T. 4 / Reprintnoe vosproizvedenie izdaniya BrokgauzaEfrona. - M.: TERRA, 1994. - $592 \mathrm{~s}$.

\footnotetext{
24 Последовательное развитие данного концепта проявляет проблемность, например, терминологической формулы «состав правонарушения».
} 
6. Ozhegov S.I. i Shvedova N.Yu. Tolkovyi slovar' russkogo yazyka: 80000 slov i frazeologicheskikh vyrazhenii / Rossiiskaya akademiya nauk. Institut russkogo yazyka im. V.V. Vinogradova. - 4-e izd., dopolnennoe. - M.: Azbukovnik, 1999. - 944 s.

7. Syrykh V.M. Teoriya gosudarstva i prava: Uchebnik dlya vuzov. - 4-e izd., ster. - M.: ZAO Yustitsinform, 2005. - 704 s.

8. Tedeev A.A., Parygina V.A. Nalogovoe pravo: Uchebnik / A.A. Tedeev, V.A. Parygina. - M.: Izd-vo Eksmo, 2004. - 864 s. .

9. Tolstoi Yu.K. K teorii pravootnosheniya. - Leningrad: Izd-vo Leningradskogo Un-ta. - 1959. - 88 s.

10. Khalfina R.O. Obshchee uchenie o pravootnoshenii. - M.: Yur. lit. - 1974. - 340 s.

Материал поступил в редакцию 22 августа 2013 г. 